\title{
A oficina educativa no enfrentamento do bullying: uma experiência com adolescentes institucionalizados
}

\author{
The educational workshop in facing bullying: an \\ experience with institutionalized adolescents
}

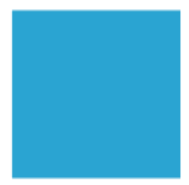

Revista

Extensão em Foco

\author{
Elaine Cristina Dias Franco ${ }^{1}$, Edilene Aparecida Araújo da Silveira ${ }^{2}$, Eduardo Augusto \\ da Mata Coelho ${ }^{3}$, Larissa Vitória Braga Alves $^{4}$, Letícia Eugênio Mota ${ }^{5}$, Nicole \\ Francinne Marques Moura ${ }^{6}$, Osiel Ferreira Antunes ${ }^{7}$
}

\begin{abstract}
RESUMO
O bullying é definido como uma subcategoria de violência, comum aos espaços escolares executada em uma relação desigual de poder que pode gerar consequências para crianças e adolescentes. O objetivo desse estudo foi relatar a experiência da aplicação da oficina educativa sobre bullying com adolescentes. Trata-se de um estudo na modalidade de relato de experiência de caráter descritivo e analítico. Os participantes foram 12 adolescentes institucionalizados, do sexo masculino, com idades entre 10 a 17 anos atendidos pelo Programa de Extensão ACOLHER. Observou-se o envolvimento dos adolescentes por meio de expressões faciais e corporais, relatos de experiências, discussões e dramatizações de situações de bullying. Notou-se que o bullying permeia o cotidiano dos adolescentes. Na oficina eles foram conduzidos a refletir sobre os papéis que exercem durante a prática do bullying e incentivados a adotar condutas que envolvam o respeito ao próximo e a diversidade. Conclui-se que ao discutir essa temática com os adolescentes houve a possibilidade de instrumentalizá-los para desenvolvimento de habilidades para o enfrentamento do bullying, inserindo-os de forma equânime na sociedade como protagonistas na redução da violência e suas consequências no meio em que vivem.
\end{abstract}

Palavras-chave: Abrigo. Institucionalização. Adolescentes. Bullying. Educação em Saúde.

\section{ABSTRACT}

Bullying is defined as a subcategory of violence, common to school spaces performed in an unequal power relationship that can have consequences for children and adolescents. This study aimed to report the experience of applying the educational workshop on bullying with adolescents. This is a study in the form of an experience report of a descriptive and analytical character. The participants were 12 institutionalized adolescents, male, aged between 10 and 17 years attended by the ACOLHER Extension Program. The involvement of adolescents was observed through facial and body expressions, reports of experiences, discussions, and dramatizations of bullying situations. It was noted that bullying permeates the daily lives of adolescents. At the workshop, they were led to reflect on the roles they play during the practice of bullying and encouraged to adopt behaviors that involve respect for others and diversity. It is concluded that when discussing this theme with adolescents, it was possible to instrumentalize them to develop skills to face bullying, inserting them equally in society as protagonists in the reduction of violence and its consequences in the environment in which they live.

Keywords: Shelter. Institutionalization. Adolescent. Bullying. Health Education.

\footnotetext{
${ }^{1}$ Doutora em enfermagem pela Universidade Federal de Minas Gerais (UFMG), Divinópolis, Minas Gerais, Brasil. E-mail: elainefranco@ufsj.edu.br. Orcid:http://orcid.org/ 0000-0001-8744-7726

${ }^{2}$ Doutora em enfermagem psiquiátrica pela Universidade de São Paulo (USP). Divinópolis, Minas Gerais, Brasil. E-mail: edileneap@ufsj.edu.br. Orcid: http://orcid.org/0000-0001-7378-2240
} 
${ }^{3}$ Acadêmico de Enfermagem da Universidade Federal de São João Del Rei (UFSJ). Divinópolis, Minas Gerais, Brasil. E-mail: dudulaug@gmail.com. Orcid: http://orcid.org/0000-0002-1608-2472

${ }^{4}$ Acadêmica de Enfermagem da Universidade Federal de São João Del Rei (UFSJ). Divinópolis, Minas Gerais, Brasil. E-mail: larissa.vitoria.braga@gmail.com. Orcid: http://orcid.org/0000-0001-7595-3701

5 Acadêmica de Enfermagem da Universidade Federal de São João Del Rei (UFSJ). Divinópolis, Minas Gerais, Brasil. E-mail: leticiamotae@gmail.com. Orcid: http://orcid.org/0000-0001-9257-5992

${ }^{6}$ Acadêmica de Enfermagem da Universidade Federal de São João Del Rei (UFSJ). Divinópolis, Minas Gerais, Brasil. E-mail: nicolefrancinnemoura@gmail.com. Orcid: http://orcid.org/0000-0002-9743-2226

${ }^{7}$ Acadêmico de Enfermagem da Universidade Federal de São João Del Rei (UFSJ). Divinópolis, Minas Gerais, Brasil. E-mail: osielferantunes@gmail.com. Orcid: http://orcid.org/0000-0002-4025-8079

\section{INTRODUÇÃOO}

Considerado como uma forma de violência, o bullying se tornou um tema de relevância social e tem sido explorado por diversos estudiosos nacionais e internacionais que buscam, de modo geral, compreendê-lo como um fenômeno social que acomete crianças e adolescentes e acarreta numerosas consequências para agressores, vítimas e expectadores. Esses estudos têm demonstrado que o bullying configura-se como uma subcategoria de violência, com atos repetitivos, agressivos e executados em uma relação assimétrica de poder entre pares que podem acarretar consequências à saúde física e psicológica das vítimas (ALENCASTRO et al 2020; QUEIROZ; MOTA, 2019; HELLSTRÖM; PERSSON; HAGQUIST, 2015; FU; CHAN; IP, 2014).

A prática do bullying se manifesta de maneira direta e indireta. As formas diretas mais comuns são a agressão física, como brigas e empurrões; a agressão verbal, efetivada por meio de xingamentos, determinação de apelidos e importunação, e; a agressão sexual. De forma indireta são observadas as agressões psicológicas e morais representadas por situações de exclusão, isolamento, invasão e divulgação de informações privativas das vítimas, difamação e injúrias. Outro tipo de bullying de ocorrência importante é o cyberbullying onde a violência entre pares ocorre dentro do espaço virtual (MARCOLINO et al, 2018; HELLSTRÖM; PERSSON; HAGQUIST, 2015; OLIVEIRA; COSTA; OLIVEIRA, 2014).

O lócus para a prática do bullying mais comum é o ambiente escolar. Acredita-se que a permanência do(a) adolescente nesse ambiente por várias horas possa ser um fator que favoreça o surgimento recorrente de conflitos e intimidações sistemáticas (bullying) com seus pares (ALENCASTRO et al, 2020; CAVALCANTI et al, 2019). A adolescência é definida pela Organização Mundial da Saúde como o período do ciclo da 
vida que corresponde ao intervalo de idade entre os 10 e 19 anos incompletos (WHO, 2015).

Nesse período, os adolescentes apresentam diversidade de grupos, atitudes, comportamentos, gostos, valores e filosofia de vida, bem como, buscam respostas para a sua existência, colocam em xeque os paradigmas sociais e culturais e neste movimento, por vezes se rebelam e em tantos outros momentos, se revelam como seres em (trans)formação. Na indecisão de qual caminho tomar, o adolescente se arrisca, oscilando entre condutas de risco assumido (decorrente de uma ação pensada) e do risco insensato em que de forma inconsequente se expõe (SIEGEL, 2016; COSTA et al, 2019). Diante das indecisões e das experiências que lhe são ofertadas por seus pares, família e sociedade, surgem as ocorrências do bullying onde os adolescentes assumem em seus cotidianos papéis de agressores, vítimas e espectadores (ALENCASTRO et al, 2020; HELLSTRÖM; PERSSON; HAGQUIST, 2015; FU; CHAN; IP, 2014).

Dado que a prática do bullying ocorre principalmente com sujeitos vulneráveis, seja no âmbito escolar, familiar, social e/ou econômico, destaca-se neste estudo os adolescentes que estão em acolhimento institucional. O fato de morar em uma Casa de Acolhimento coloca em evidência estigmas sociais, atribuídos ao público morador de "abrigos/orfanatos", relacionados com o abandono, a ausência de estrutura familiar, a pobreza, a falta de conhecimento, a incapacidade de aprender e a impossibilidade de apresentar um futuro promissor (FERNANDES et al, 2019; ACIOLI et al, 2019).

Diante das vulnerabilidades que compõe o cotidiano da institucionalização de crianças e adolescentes, desde o ano 2016, o Curso de Enfermagem da Universidade Federal de São João del Rei (UFSJ) desenvolve o Programa de Extensão ACOLHER. O programa apresenta como objetivo primário promover o crescimento e o desenvolvimento biopsicossocial saudável das crianças e adolescentes em acolhimento institucional. A equipe de trabalho é formada por duas docentes enfermeiras, um residente dentista que está em formação para assistência ao adolescente, doze estudantes do curso de graduação em enfermagem e parceiros externos como Polícia Militar, Corpo de Bombeiros, SENAC, comércio local, dentre outros. São desenvolvidas semanalmente consultas de enfermagem associadas com oficinas educativas e atividades recreativas que apresentam temáticas 
previamente definidas pela equipe a partir das informações coletadas nas consultas e interações com as crianças e adolescentes.

Dentre as experiências vivenciadas pela equipe, este estudo tem como objetivo relatar a experiência da aplicação da oficina educativa sobre bullying com adolescentes institucionalizados.

\section{MÉTODOS}

Trata-se de um estudo na modalidade relato de experiência de caráter descritivo e analítico, desenvolvido pela equipe de trabalho do Programa de Extensão ACOLHER. O programa ACOLHER tem como público-alvo crianças e adolescentes que estão institucionalizados em Casas de Acolhimento de um munícipio da região centro-oeste de Minas Gerais. Em junho de 2019, doze adolescentes, do sexo masculino, com idades entre 10 a 17 anos, pertencentes a Casa de Acolhimento A, foram convidados a participar de uma oficina relacionada com a temática - Bullying.

Entende-se como oficina, um espaço que promove a (re)construção do conhecimento por meio da vivência de situações concretas e significativas que são permeadas pelo tripé sentir-pensar-agir (PAVIANI; FONTANA, 2009). A adoção da oficina como estratégia de ensino, visa colocar o adolescente como agente ativo e reflexivo no processo de aprendizagem partindo da sua realidade e experiências vivenciadas no contexto do bullying. Buscou-se com a atividade instrumentalizar os adolescentes para o enfrentamento de situações de bullying por meio da reflexão e conscientização acerca desse tema.

Para o planejamento e execução da oficina, adotou-se como referencial teórico o conceito de aprendizagem significativa de David Ausubel, reiterada, no Brasil, por Marco Antônio Moreira. Para o teórico, os educadores devem partir dos conhecimentos prévios do indivíduo e buscar estratégias de ensino que promovam a interação entre um novo conhecimento e aquele já adquirido. Com o objetivo de que o aprendizado possa ser significativo, deve-se despertar o interesse do aprendiz pelo tema e utilizar de materiais e recursos que tragam significados à temática (MOREIRA, 2011).

Assim, a equipe partiu do pressuposto de que os adolescentes já teriam um conceito preestabelecido sobre o bullying e conheciam as suas consequências enquanto vítima, 
agressor ou espectador. Considerou-se como ponto de partida o conhecimento prévio dos adolescentes com vistas a ampliação, (re)construção e (re)significação de saberes adquiridos em outras vivências, bem como a aquisição de novos conhecimentos.

A oficina ocorreu na sala de televisão da casa de acolhimento e constou de duas etapas.

\section{Etapa 1 - Sessão de cinema ACOLHER}

A fim de proporcionar aos adolescentes a vivência de estar em uma sala de cinema, foram utilizados alguns recursos tecnológicos como computador, retroprojetor e caixa de som. Associado aos recursos tecnológicos foi disponibilizada pipoca durante a exibição do filme. Houve a organização prévia do ambiente de forma a torná-lo confortável, tranquilo e acolhedor. Os sofás foram reposicionados para favorecer a participação e conforto e, de forma complementar, também foram organizados espaços com almofadas e tapetes para aqueles que desejassem deitar ou se acomodar. No cinema criado pela equipe estava em cartaz o filme "Extraordinário" (Figura 1).

Figura 1 - Filme Extraordinário

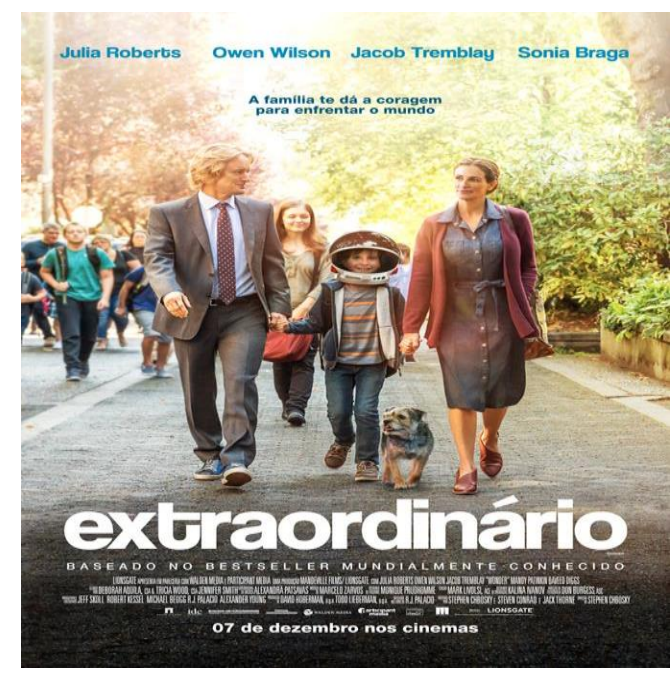

Fonte: http://www.adorocinema.com/filmes/filme-232132/

Trata-se de um filme lançado no ano de 2017, que conta a história de um garoto, Puggie Pullman que nasceu com uma deformidade facial. Ao completar 10 anos de idade, 
ele é inserido em um ambiente escolar e precisa lidar com os olhares de estranheza de seus colegas, o sentimento de isolamento e o bullying. No entanto, também é no ambiente escolar, com o apoio familiar e de amigos, que Auggie desenvolve habilidades para o enfretamento e superação de suas dificuldades, dentre elas, o bullying.

\section{Etapa 2 - Roda de Conversa e Criatividade}

Após a exibição do filme, assegurando a manutenção do conforto e integração dos adolescentes, a equipe do ACOLHER deu início a uma roda de conversa. A roda de conversa tem por finalidade permitir que os participantes expressem suas impressões, conceitos, opiniões e concepções sobre o tema proposto, bem como favorece a reflexão dos pontos apresentados pelo grupo (MELO; CRUZ, 2014). Para essa etapa foram desencadeadas três fases, sendo: Fase 1- Dramatização de casos reais de vítimas de bullying pela equipe do programa ACOLHER; Fase 2 - Discussões baseadas em experiências, relacionadas com o bullying, vivenciadas pelos adolescentes em seus cotidianos e; Fase 3- Produção criativa dos adolescentes relacionadas às suas percepções acerca do bullying.

\section{RESULTADOS E DISCUSSÃO}

A intervenção realizada com os adolescentes apresentou como finalidade primária a instrumentalização dos adolescentes para o enfrentamento de situações de bullying por meio da reflexão e conscientização acerca desse tema. Os adolescentes foram conduzidos a refletir sobre suas interações sociais; a revisitar seus saberes acerca do bullying e; a instituir movimentos de ruptura de ideias do senso comum que naturalização práticas relacionadas com brincadeiras desagradáveis, uso de apelidos, dentre outras.

O uso da estratégia do cinema com a exibição do filme - Extraordinário, representada na Figura 2, trouxe para os envolvidos uma sintonia e a aquisição de uma situação de conforto e confiança, que puderam ser explorados pela equipe ACOLHER na segunda etapa da oficina. 
Figura 2 - Sessão de Cinema

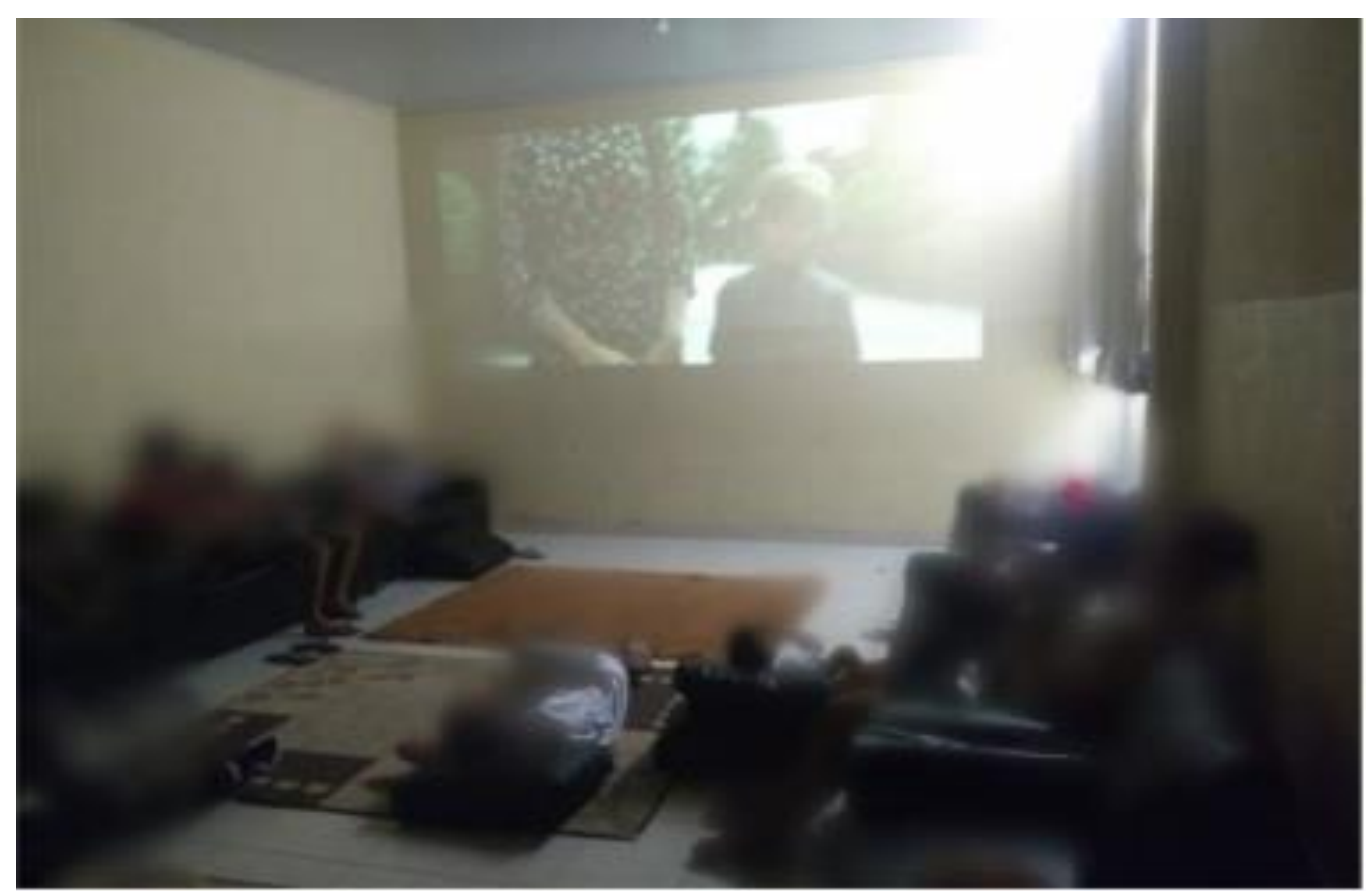

Fonte: Banco de fotos do Programa ACOLHER, 2020

Por meio do filme os adolescentes foram sensibilizados a perceber os modos como o bullying afeta as vítimas, os familiares, os agressores e os espectadores. Durante o filme comentários eram tecidos pelos adolescentes e suas expressões faciais e corporais revelaram sentimentos relacionados a raiva, tristeza e indignação. Sendo esse último percebido de modo evidente quando no filme eram exibidas cenas em que o ator principal era alvo de bullying.

No decorrer da exibição do filme alguns dos jovens relataram ser vítimas de bullying na escola. Neste caso, a condição de morar em uma casa de acolhimento era a característica que desencadeava o bullying. A institucionalização de crianças e adolescentes entra em cena quando a família não cumpre com o seu dever de proteção dos direitos da criança. Dentre os motivos para a institucionalização estão a negligência, abandono, abusos e maus-tratos (ACIOLI et al, 2019).

Ao serem instituídos novos percursos de vida para os adolescentes é comum que estes sejam vistos socialmente como "adolescentes problema" nos ambientes em que vivem e convivem, contribuindo para baixa autoestima, interferências no desempenho escolar e dificuldade de comunicação (ACIOLI et al, 2019). Em estudo realizado em 
2013, constatou-se que a evasão escolar e a infrequência de adolescentes institucionalizados possuem uma relação com as situações de estigmatização e preconceitos para com eles por parte de alunos, professores e diretores (FURLAN; SOUZA, 2013).

Durante a exibição do filme também houve o relato de que em algumas circunstâncias os adolescentes adotavam o papel de espectadores por medo de se posicionarem. Eles acreditam que ao adotar uma posição em defesa da vítima tornam explícitas as atitudes do agressor, o que pode acarretar represálias ao espectador. Alinhados aos relatos dos adolescentes, estudos mostram que o papel de espectador é adotado com frequência pelos jovens, sendo usados como justificativa para esse comportamento o medo de se tornarem vítimas e o entendimento que esta interferência não provocaria ruptura na prática do bullying pelo agressor (OLIVEIRA et al, 2018; ZEQUINÃO et al, 2017; ZEQUINÃO et al, 2016).

Embora se percebessem como vítimas ou espectadores, no intervalo entre a primeira e segunda etapa da oficina, foram observadas, entre os adolescentes, situações relacionadas com a imposição de apelidos e brincadeiras que causavam desconforto para os envolvidos. Sendo assim, foi observado que eles se tornavam agressores sem perceber as consequências que resultaria mediante a esse posicionamento. A associação dos estigmas sociais conferidos aos adolescentes institucionalizados com suas experiências de vida fragilizadas e marcadas por riscos, leva esse público a assumir, em algumas circunstâncias, a condição de vítimas em situações que envolvem o bullying e em outras, como forma de proteção, passam à condição de agressores e/ou espectadores (UFSJ, 2019; FERNANDES et al, 2019)

A segunda etapa da oficina também ocorreu no espaço da sala de televisão. Os adolescentes mostravam-se interessados pelas atividades propostas com uma participação efetiva nas três fases que compuseram essa segunda etapa. Na primeira fase quatro integrantes da equipe ACOLHER, por meio da dramatização, apresentaram o relato de um caso real de bullying selecionado em blogs e sites de jornais. As vítimas apresentavam condições que eram usadas pelo agressor como dispositivo para a prática do bullying, como por exemplo deficiência física, baixo rendimento escolar, aparência física fora dos padrões de aceitação do agressor e obesidade. Buscou-se com a dramatização oportunizar 
aos adolescentes a vivência, ancorada na observação, dos desfechos do bullying na vida dos envolvidos.

No decorrer da dramatização observou-se a atenção aumentada e a identificação com alguns pontos das vivências retratadas. A sensibilização dos adolescentes permitiu que fossem iniciados diálogos que tratavam de seus cotidianos e suas práticas em relação ao bullying, assumindo os diversos papéis que o compõem (Figura 3).

Figura 3 - Roda de Conversa

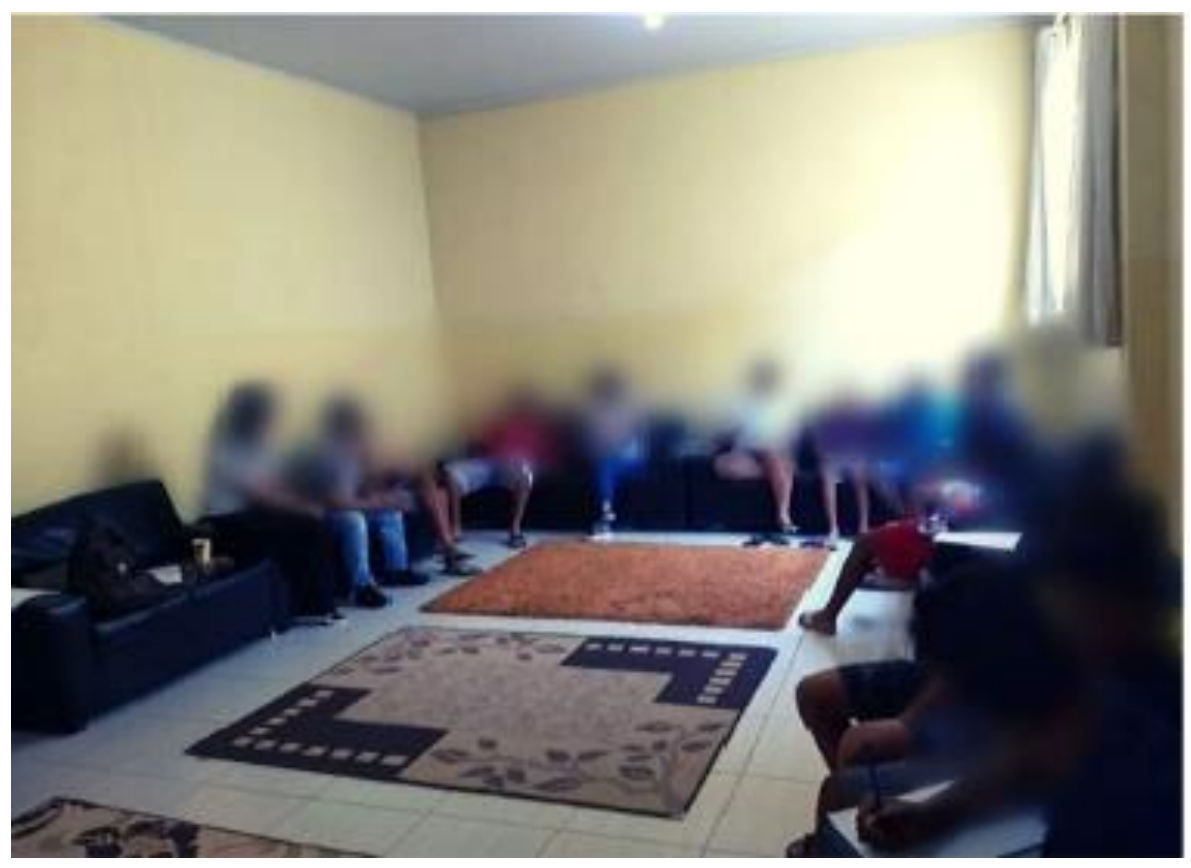

Fonte: Banco de fotos do Programa ACOLHER, 2020

Neste momento eles expressaram o desconforto relacionado a situações que envolviam o uso de apelidos pejorativos e brincadeiras que envolviam eles próprios e/ou seus pares, bem como disseram de sentimentos relacionadas a tristeza, medo e inferioridade.

De modo semelhante a outros estudos, percebe-se que ao dar voz aos adolescentes, na roda de conversa, as vítimas conseguiram, de modo peculiar, demonstrar suas insatisfações e seus sentimentos de tristeza, baixa autoestima e medo em relação aos comportamentos de outros adolescentes que, por vezes, ocupavam a posição de 
agressores (LEAL et al, 2016). Observa-se que ao ser constituído como um fenômeno social e de grupo, os comportamentos adotados pelos envolvidos com o bullying sejam eles vítimas, agressores ou espectadores, terão influência na manutenção e/ou interrupção dessa prática social (ZEQUINÃO et al, 2017)

Finalizadas as discussões, teve início a terceira fase da roda de conversa. Nesta etapa os adolescentes foram convidados a usar a criatividade para demonstrar suas percepções acerca do bullying, considerando sua definição e suas consequências para os envolvidos. Como regra final definiu-se que as criações seriam expostas pelos autores para os demais adolescentes. Para essa etapa eles tiveram acesso a revistas, recortes de jornais, folhas sulfite, lápis de cor, cola, pincel, borracha, lápis preto e caneta.

Depois de 15 minutos houve a apresentação dos produtos. Foram realizadas leitura de gibis, exibição de alguns desenhos e textos e uma dramatização com uso da prosopopeia também chamada de personificação. A prosopopeia foi apresentada por meio de uma folha em branco que, segundo o adolescente, representaria uma pessoa que nunca havia se deparado com ações de bullying. Em seguida o adolescente amassou a folha e logo depois a abriu e alisou junto ao seu corpo. Durante esse movimento de dar a folha novamente um formato próximo do original, o adolescente verbalizou para todos os expectadores que a folha representava uma pessoa que havia sofrido bullying e as marcas do amassado eram as cicatrizes definitivas deixadas por aquelas agressões.

Sabe-se que a vivência do bullying acarreta, para os envolvidos, consequências que comprometem seu desempenho escolar, o desenvolvimento psicossocial, bem como sua saúde com desenvolvimento de quadros de ansiedade, crise do pânico, distúrbios alimentares, automutilação, dentre outros (ALENCASTRO et al, 2020; QUEIROZ; MOTA, 2019; OLIVEIRA et al, 2018). Torna-se necessário o desenvolvimento de estratégias que promovam o respeito entre os indivíduos, para que possam expressar seus sentimentos, comportamentos e vivenciar sua identidade afetiva-sexual, sem sofrer qualquer tipo de agressão por isso.

Desse modo, a proposição de estratégias que favoreçam a troca de experiências entre adolescentes, o acesso às informações que tratem do bullying e seus desfechos na vida dos envolvidos, poderá potencializar o uso de medidas de enfrentamento do bullying pelos envolvidos e consequentemente contribuir com a criação de um ambiente seguro e 
empático, ambiente este capaz de formar cidadãos aptos a respeitar a singularidade e a diversidade humana (OLIVEIRA; COSTA; OLIVEIRA, 2014; BRÊTAS; MORAES, 2020).

\section{CONSIDERAÇÕES FINAIS}

A escolha da oficina como estratégia para a intervenção e o uso diversificado de métodos de ensino e interação com os adolescentes permitiu que a temática bullying pudesse ser visualizada a partir de suas vivências, dando sentido e significado para as medidas de boa convivência social, para valores como respeito e condutas como a empatia e o acolhimento do outro. As atividades propiciaram a reflexão dos jovens acerca do tema bullying, uma vez que devido as suas histórias de vida marcadas pela violência, abandono e negligência tornam a violação de seus direitos muitas vezes naturalizada aos seus olhos. A reflexão proposta sobre as atitudes para com o outro levou à minimização dos danos decorrentes da história pregressa e da institucionalização. A educação em saúde torna os adolescentes mais conscientes em relação à violência que sofrem e praticam.

A oficina apresentou resultados positivos em relação à reflexão e modificação de comportamentos desses jovens, além de dados significativos que justifiquem a importância da realização de educação continuada sobre essa temática. Dessa forma, ao discutirmos bullying com os adolescentes institucionalizados em situação de vulnerabilidade podemos inseri-los de forma equânime na sociedade como protagonistas na redução da violência e suas consequências na sociedade, promovendo assim, uma cultura de paz.

\section{REFERÊNCIAS}

ACIOLI, R. M. L. et al. Tempo de acolhimento e características dos adolescentes acolhidos por tipo de serviços institucionais. Rev. Ciência \& Saúde Coletiva, Rio de Janeiro, v. 24, n. 2, p. 553-562, fev. 2019. Disponível em: https://doi.org/10.1590/1413 81232018242.06402017. Acesso em: 24 abr. 2020.

ALENCASTRO, L. C. S. et al. Theater of the Oppressed and bullying: nursing performance in school adolescent health. Rev. Brasileira de Enfermagem, Brasília, v. 
73, n. 1, p. 1-7, 2020. Disponível em: http://dx.doi.org/10.1590/0034-7167-2017-0910. Acesso em: 16 abr. 2020.

BRÊTAS, J. R. S.; MORAES, S. P. Preconceito e bullying no ambiente escolar. Rev. Educação, Guarulhos, v. 15, n. 1, p. 147-157, 2020. Disponível em: http://dx.doi.org/10.33947/1980-6469-v15n1-4015. Acesso em: 23 abr. 2020.

CAVALCANTI, J. G. et al. Bullying no Contexto da Adolescência: Um Estudo das Representações Sociais. Revista de Psicologia da IMED, Passo Fundo, v. 11, n. 2, p. 96-114, jul/dez 2019. Disponível em: https://doi.org/10.18256/21755027.2019.v11i2.3287. Acesso em: 24 abr. 2020.

COSTA, C. C. et al. Perfil biopsicossocial de crianças e adolescentes institucionalizados. Rev. Eletrônica Acervo Saúde, v. 11, n. 17, p. 1-7, out. 2019. Disponível em: https://doi.org/10.25248/reas.e1671.2019. Acesso em: 17 abr. 2020.

FERNANDES, A. O. et al. Estresse em adolescentes abrigados. Rev. Adolescência \& Saúde, Rio de Janeiro, v. 12, n. 4, p. 65-75, out/dez 2015. Disponível em: http://www.adolescenciaesaude.com/detalhe_artigo.asp?id=536. Acesso em: 22 abr.2020.

FU, King-wa; CHAN, Chung-hong; IP, P. Exploring the relationship between cyberbullying and unnatural child death: an ecological study of twenty-four European countries. Rev. BMC Pediatrics, v. 14, n. 195, p. 1-6, 2014. Disponível em: https://bmcpediatr.biomedcentral.com/track/df/10.1186/1471-2431-14-195. Acesso em: 19 abr. 2020.

FURLAN, V.; SOUZA, T. R. DE P. Exclusão/Inclusão Social: Políticas Públicas de acolhimento institucional dirigidas à Infância e Juventude. Rev. Diálogo, Canoas, v. 1, n. 23, p. 35-48, ago. 2013. Disponível em: https://revistas.unilasalle.edu.br/index.php/Dialogo/article/view/909/901. Acesso em: 19 abr. 2020.

HELLSTRÖM, L.; PERSSON, L.; HAGQUIST, C. Understanding and defining bullying - adolescents' own views. Rev. Archives of Public Health, n. 73, v. 4, p. 2-9, 2015. https://archpublichealth.biomedcentral.com/track/pdf/10.1186/2049-3258-73-4. Acesso em: 17 abr. 2020. 
MELO, M. C. H. de; CRUZ, G. de C. Roda de Conversa: uma proposta metodológica para a construção de um espaço de diálogo no Ensino Médio. Rev. Imagens da Educação, v. 4, n. 2, p. 31-39, maio 2014. Disponível em: https://doi.org/10.4025/imagenseduc.v4i2.22222. Acesso em: 17 abr. 2020.

LEAL, S. D. C. et al. Conscientização e Sensibilização sobre o Bullying em Alunos do Ensino Fundamental: Um Relato de Experiência. In: Congresso Internacional de Educação Inclusiva, 2, 2016, Campina Grande. Disponível em: https://editorarealize.com.br/revistas/cintedi/trabalhos/TRABALHO_EV060_MD1_SA 3_ID1081_23102016155059.pdf. Acesso em: 24 abr. 2020.

MARCOLINO, E. de C. et al. Bullying: prevalência e fatores associados à vitimização e à agressão no cotidiano escolar. Rev. Texto \& contexto enfermagem, Florianópolis, v. 27, n. 1, p. 1-10, mar. 2018. Disponível em: https://doi.org/10.1590/0104-07072018005500016. Acesso em: 23 abr. 2020.

MOREIRA, M.A. Aprendizagem Significativa: a Teoria e Textos Complementares. São Paulo: Editora Livraria da Física. 2011. 179p.

OLIVEIRA, M. C. M.; COSTA, J. R. S.; OLIVEIRA, M. M. Bullying: análise do comportamento e mudanças de hábitos nas relações entre crianças em uma comunidade escolar. Rev. Extensão em Foco, Curitiba, n. 10, v. 1, p. 18-36, jul./dez. 2014. Disponível em: http://dx.doi.org/10.5380/ef.v0i10.29915. Acesso em: 20 abr. 2020.

OLIVEIRA, W. A, et al. Modos de explicar o bullying: análise dimensional das concepções de adolescentes. Rev. Ciência \& Saúde Coletiva, Rio de Janeiro, v. 23, n. 3, p. 751-761, 2018. Disponível em: https://doi.org/10.1590/1413-81232018233.10092016. Acesso: 23 abr. 2020.

PAVIANI, N. M. S.; FONTANA, N. M. Oficinas pedagógicas: relato de uma experiência. Rev. Conjectura, Caxias do Sul, v. 14, n. 2, maio/ago. 2009. Disponível em: http://www.ucs.br/etc/revistas/index.php/conjectura/article/viewFile/16/15. Acesso em: 23 abr. 2014.

QUEIROZ, T. G. F.; MOTA, R. C. C. Um sonho silenciado: as consequências do bullying na vida social da criança e do adolescente. Rev. FACISA ON-LINE, Barra do Garças, v. 8, n. 1, p. 92-118, jan./jul. 2019. Disponível em: http://periodicos.unicathedral.edu.br/revistafacisa/article/view/247/203. Acesso em: 19 abr. 2020. 
SIEGEL, D.J. A essência da adolescência. In: Cérebro Adolescente: a coragem e a criatividade da mente dos 12 aos 14 anos. São Paulo: nVersos, 2016. Cap.1. p.7-64.

WHO. World Health Organization. The global strategy for women's, children's and adolescents' health (2016-2030). Every Woman Every Child. Data de publicação: 2015, 108p. Disponível em: http://globalstrategy.everywomaneverychild.org/. Acesso em: 20 abr. 2020.

ZEQUINÃO, M. A. et al. Bullying escolar: um fenômeno multifacetado. Rev. Educação e Pesquisa, São Paulo, v. 42, n. 1, p. 181-198, mar. 2016. Disponível em: https://doi.org/10.1590/S1517-9702201603138354. Acesso em: 20 abr. 2020.

ZEQUINÃO, M. A. et al. Desempenho escolar e bullying em estudantes em situação de vulnerabilidade social. Journal of Human Growth and Development, v. 27, n. 1, p. 19-27, 2017.Disponível em: http://dx.doi.org/10.7322/jhgd.127645. Acesso em: 19 abr. 2020. 
DOI: http://dx.doi.org/10.5380/ef.v0i20

Recebido em: 24 de dezembro de 2019.

Aceito em: 05 de agosto de 2020. 